\title{
Advances in Radar Remote Sensing of Agricultural Crops: A Review
}

\author{
Thota Sivasankar, *, Dheeraj Kumar ${ }^{*}$, Hari Shanker Srivastava ${ }^{\#}$, Parul Patel ${ }^{\$}$ \\ \# Agriculture \& Soils Department, Indian Institute of Remote Sensing (ISRO), \\ Dehradun-248001, Uttarakhand, India \\ E-mail: siva.iirs@gmail.com; hari.irso@gmail.com \\ *Department of Mining Engineering, Indian Institute of Technology (Indian School of Mines), \\ Dhanbad-826004, Jharkhand, India \\ E-mail:dheeraj@dkumar.org \\ ${ }^{\$}$ Space Applications Centre (ISRO), Ahmedabad-380015, Gujarat, India \\ E-mail:parul_isro@gmail.com
}

\begin{abstract}
There are enormous advantages of a review article in the field of emerging technology like radar remote sensing applications in agriculture. This paper aims to report select recent advancements in the field of Synthetic Aperture Radar (SAR) remote sensing of crops. In order to make the paper comprehensive and more meaningful for the readers, an attempt has also been made to include discussion on various technologies of SAR sensors used for remote sensing of agricultural crops viz. basic SAR sensor, SAR interferometry (InSAR), SAR polarimetry (PolSAR) and polarimetric interferometry SAR (PolInSAR). The paper covers all the methodologies used for various agricultural applications like empirically based models, machine learning based models and radiative transfer theorem based models. A thorough literature review of more than 100 research papers indicates that SAR polarimetry can be used effectively for crop inventory and biophysical parameters estimation such are leaf area index, plant water content, and biomass but shown less sensitivity towards plant height as compared to SAR interferometry. Polarimetric SAR Interferometry is preferable for taking advantage of both SAR polarimetry and SAR interferometry. Numerous studies based upon multi-parametric SAR indicate that optimum selection of SAR sensor parameters enhances SAR sensitivity as a whole for various agricultural applications. It has been observed that researchers are widely using three models such are empirical, machine learning and radiative transfer theorem based models. Machine learning based models are identified as a better approach for crop monitoring using radar remote sensing data. It is expected that the review article will not only generate interest amongst the readers to explore and exploit radar remote sensing for various agricultural applications but also provide a ready reference to the researchers working in this field.
\end{abstract}

Keywords - biophysical parameters retrieval; crop inventory; synthetic aperture radar (SAR); synthetic aperture radar interferometry (InSAR); SAR polarimetry (PolSAR); polarimetric SAR interferometry (PolInSAR).

\section{INTRODUCTION}

An accurate estimation of crop yield is becoming crucial in developing countries to improve food security. The demand for grain is going to be nearly double of the current situation by 2050 [1]. Yield forecasting in regional and national level helps to maintain political and social stability and equity [2]. Crop yield primarily depends on the crop biophysical parameters dynamics over a period during the growing season [3]-[4]. Therefore, the spatiotemporal changes of crop biophysical parameters are required for precise yield forecasting.

In contrast to ground-based instrument measurements, remote sensing data has gained considerable importance for crop biophysical parameters retrieval by providing high spatial and temporal resolution images from local to global scales. Moreover, remote sensing data can support quantitative analyses on land-atmosphere interactions and climate models [5]. The all-weather capability of radar remote sensing makes it more suitable than all other remote sensing techniques for constant crops monitoring. For an illustration, the RADARSAT-2 temporal SAR images acquired over north India during Kharif season and its corresponding optical images are given in Figure 1. The use of SAR data for agricultural crop studies has been significantly increased after the launch of the first operational SAR sensor onboard ERS-1 in 1991. A list of few important SAR sensors, which were launched so far is 
given in Table 1. Several researchers have been investigated the sensitivity of the radar return signal towards agricultural crop characteristics [6]-[8]. Various SAR technologies like SAR polarimetry [9], SAR interferometry[10] and polarimetric SAR interferometry[11] have been developed to analyze the target characteristics from return signal properties.

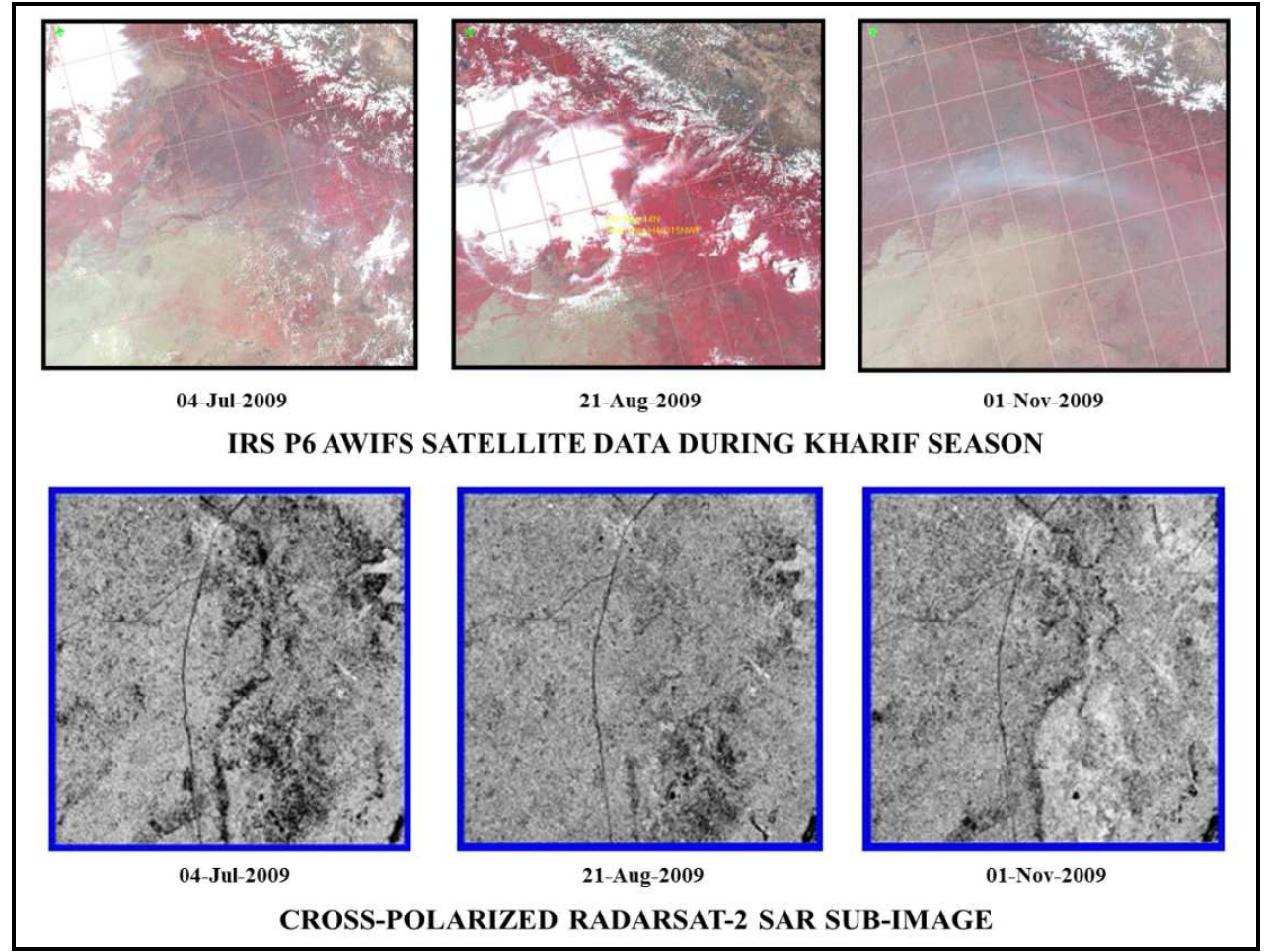

Fig. 1: Optical and Microwave remote sensing data acquired over northern India

The radar remote sensing has attained importance in various applications including agriculture [12]-[13], wetland [14]-[16] and forest [17]-[19] related studies due to its unique sensitivity to the physical, dielectric and geometric properties of various components of vegetation cover and underneath soil characteristics. It is widely comprehended that the radar return signal from an agricultural crop covered field is an effect of target parameters such are vegetation cover characteristics and underneath soil moisture [20]-[22] as well as sensor parameters such are the frequency of operation, incidence angle and polarization [23]-[24]. So, an appropriately chosen of SAR sensor parameters is required to enhance the sensitivity of SAR data to a particular application. Ground-truth sampling for biophysical parameters retrieval experiment using SAR data must be taken from sufficient large area fields. Patel and Srivastava[25], have made a detailed explanation of the approach to choose optimum field size and sample size for target parameters retrieval. Authors find it necessary to give a brief introduction on the interaction of radar signals with agricultural crop covered fields so that readers can easily understand the required combination of SAR sensor parameters and SAR technique for a specified application. With the continuation of this, the basics of SAR technologies viz. backscattering coefficients, SAR polarimetry, SAR interferometry and polarimetric SAR interferometry and the renowned research work in crop biophysical parameters retrieval are summarized.

\section{A. Influence of SAR Sensor Parameters on Interaction of Microwave Signals with Agriculture Target}

A brief knowledge of SAR sensor parameters influence on the interaction of microwave signals with various components of the crop is necessary to properly utilize radar remote sensing data for a specified application [26]-[27]. For this, a detailed discussion of the sensor parameters, such as frequency, incidence angle and polarization, and its influence on the microwave signal interaction is made in the following.

1) Frequency: The ability of the signal to penetrate through the crop cover and soil over agricultural fields depends on the frequency of operation. The relationship between microwave signal penetration depth and frequency of operation is given in Equation 1. Commonly using microwave frequencies for remote sensing applications and its corresponding frequency and wavelength range are given in Table 2. The shorter frequencies can penetrate more than the more extended microwave frequency signals through the crop cover. The shorter frequency (L-band, 1-2 GHz) can penetrate through the canopy and interact with the stem and underneath soil, while C-band (4-8 GHz) frequency signals interact more with the canopy and the longer frequency $\mathrm{X}$ band $(8-12 \mathrm{GHz})$ interacts mainly with the top of the canopy [28]-[29]. Shorter microwave frequencies such are P and Lbands can even penetrate some extent to the underneath soil. The multi-frequency SAR data can use to study the soil moisture at various depths over bare fields [30]. 
TABLE I

FEW IMPORTANT SAR SENSORS: PAST AND PRESENT

\begin{tabular}{|c|c|c|c|c|c|c|}
\hline Satellite & $\begin{array}{l}\text { Launched } \\
\text { (Year) }\end{array}$ & Sensor & Band & Polarization/s & Platform & Remark \\
\hline Seasat & 1978 & SAR & $\mathrm{L}$ & $\mathrm{HH}$ & Spaceborne & $\begin{array}{l}\text { Seasat was the first spaceborne satellite for } \\
\text { remote sensing of the Earth's oceans and had } \\
\text { on board synthetic aperture radar (SAR). }\end{array}$ \\
\hline DLR & 1988 & E-SAR & $\begin{array}{l}\mathrm{X}, \mathrm{C}, \mathrm{L} \\
\text { and P }\end{array}$ & Quad & Airborne & - \\
\hline ERS-1 & 1991 & AMI & $\mathrm{C}$ & VV & Spaceborne & The first operational spaceborne SAR sensor. \\
\hline JERS-1 & 1992 & SAR & $\mathrm{L}$ & $\mathrm{HH}$ & Spaceborne & $\begin{array}{l}\text { The first spaceborne SAR sensor which } \\
\text { operates in L-band. }\end{array}$ \\
\hline SIR-C/ X & 1994 & SAR & $\begin{array}{l}\mathrm{X}, \mathrm{C} \text { and } \\
\mathrm{L}\end{array}$ & Quad & $\begin{array}{c}\text { Space } \\
\text { Shuttle }\end{array}$ & - \\
\hline ERS-2 & 1995 & AMI & $\mathrm{C}$ & VV & Spaceborne & $\begin{array}{c}\text { In combination to ERS-1, ERS-2 provides } \\
\text { images in TanDEM mode which is supposed } \\
\text { to be one of the best options for SAR } \\
\text { interferometry. }\end{array}$ \\
\hline RADARSAT-1 & 1995 & SAR & $\mathrm{C}$ & $\mathrm{HH}$ & Spaceborne & $\begin{array}{l}\text { The first spaceborne SAR sensor which } \\
\text { allows acquiring images in multi-incidence } \\
\text { mode. }\end{array}$ \\
\hline $\begin{array}{l}\text { NASA DC-8 } \\
\text { Aircraft }\end{array}$ & 1998 & AIRSAR & $\begin{array}{l}\mathrm{P}, \mathrm{L}, \text { and } \\
\mathrm{C}\end{array}$ & Quad & Airborne & $\begin{array}{l}\text { This is for demonstrating new radar } \\
\text { technology and acquiring data for the } \\
\text { development of radar processing techniques } \\
\text { and applications. }\end{array}$ \\
\hline ENVISAT & 2002 & ASAR & $\mathrm{C}$ & $\begin{array}{c}\begin{array}{c}\text { Alternative } \\
\text { Polarization } \\
\text { (HH/VV, } \\
\text { HH/HV, } \\
\text { VV/VH) }\end{array} \\
\end{array}$ & Spaceborne & $\begin{array}{l}\text { The first spaceborne SAR sensor which } \\
\text { allows acquiring in multi-incidence and multi- } \\
\text { polarized modes. }\end{array}$ \\
\hline DLR & 2006 & F-SAR & $\begin{array}{l}\mathrm{X}, \mathrm{C}, \mathrm{S}, \mathrm{L} \\
\quad \text { and } \mathrm{P}\end{array}$ & Quad & Airborne & - \\
\hline ALOS & 2006 & PALSAR & $\mathrm{L}$ & Quad & Spaceborne & - \\
\hline TerraSAR-X & 2007 & SAR & $\mathrm{X}$ & $\mathrm{HH}$ & Spaceborne & $\begin{array}{l}\text { Dual - depending on imaging mode quadruple } \\
\text { is available as advanced polarisation mode for } \\
\text { dedicated acquisition campaigns }\end{array}$ \\
\hline $\begin{array}{c}\text { NASA } \\
\text { Gulfstream III } \\
\text { aircraft (C- } \\
\text { 20A/G-III) }\end{array}$ & 2007 & UAVSAR & $\mathrm{L}$ & Quad & Airborne & $\begin{array}{l}\text { This instrument was designed primarily to } \\
\text { accurately map crustal deformations } \\
\text { associated with natural hazards, such as } \\
\text { volcanoes and earthquakes. }\end{array}$ \\
\hline RADARSAT-2 & 2007 & SAR & $\mathrm{C}$ & Quad & Spaceborne & - \\
\hline TanDEM-X & 2010 & SAR & $\mathrm{X}$ & Quad & Spaceborne & $\begin{array}{l}\text { TerraSAR-X and TanDEM-X will allow the } \\
\text { generation of WorldDEM, the global digital } \\
\text { elevation models (DEMs). }\end{array}$ \\
\hline JSC G-III & 2012 & AirMOSS & $\mathrm{P}$ & Quad & Airborne & $\begin{array}{l}\text { NASA's AirMOSS radar measures root-zone } \\
\text { soil moisture which helps to study the overall } \\
\text { carbon exchange }\end{array}$ \\
\hline RISAT-1 & 2012 & SAR & $\mathrm{C}$ & $\begin{array}{l}\text { Dual, Quad \& } \\
\text { Hybrid }\end{array}$ & Spaceborne & $\begin{array}{l}\text { The world's first spaceborne satellite onboard } \\
\text { hybrid polarimetric SAR architecture. }\end{array}$ \\
\hline ALOS-2 & 2014 & PALSAR-2 & $\mathrm{L}$ & Quad & Spaceborne & 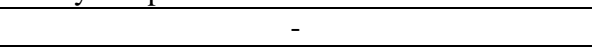 \\
\hline Sentinel-1A & 2014 & SAR & $\mathrm{C}$ & Quad & Spaceborne & $\begin{array}{l}\text { Sentinel-1 was launched to provide continuity } \\
\text { of data from ERS and Envisat missions, with } \\
\text { further enhancements regarding revisit, } \\
\text { coverage, timeliness, and reliability of service. }\end{array}$ \\
\hline Sentinel-1B & 2016 & SAR & $\mathrm{C}$ & Quad & Spaceborne & - \\
\hline
\end{tabular}

TABLE II

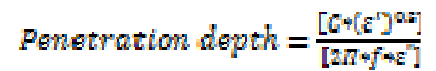

Where: $\mathrm{C}=3 \times 10^{\wedge} 8 \mathrm{~m} / \mathrm{s} ; \varepsilon^{\prime}=$ Real part of dielectric constant; $f=$ SAR sensor frequency of operation and $\varepsilon "=$ Imaginary part of dielectric constant.
MICROWAVE FREQUENCY BANDS

\begin{tabular}{|c|c|c|c|}
\hline S.No. & Band & $\begin{array}{c}\text { Frequency } \\
(\mathbf{G H z})\end{array}$ & $\begin{array}{c}\text { Wavelength } \\
(\mathbf{c m})\end{array}$ \\
\hline 1 & $\mathrm{P}$ & $0.23-1$ & $3-130$ \\
\hline 2 & $\mathrm{~L}$ & $1-2$ & $15-30$ \\
\hline 3 & $\mathrm{~S}$ & $2-4$ & $7.5-15$ \\
\hline 4 & $\mathrm{C}$ & $4-8$ & $3.75-7.5$ \\
\hline 5 & $\mathrm{X}$ & $8-12.5$ & $2.4-3.75$ \\
\hline
\end{tabular}


2) Incidence angle: The incidence angle of the SAR sensor has a considerable influence on the microwave signal interaction with the agricultural target. At low incidence angle, microwave signals can interact with the underneath soil by passing through the gaps between plants. Whereas at the high incidence angle, the return signal is highly influenced by the crop cover than the underneath soil characteristics due to increase in signal propagation length through crop cover (as shown in Fig. 2). Several experimental results have been concluded that low incidence SAR data is more sensitive to the underneath soil moisture
[30]-[31] and high incidence angle data is more sensitive to the crop characteristics [32]-[33]. Very high incidence angle SAR data is not suitable for crop biophysical parameters retrieval due to the possibility of early saturation. Using a single date, single incidence angle SAR data has a limitation in resolving the contribution of a specific target parameter in the backscattering coefficient due to the effect of several target parameters [34]. Thus, investigators evaluating the potential of multi-incidence angle SAR data for qualitative and quantitative studies of agriculture target.

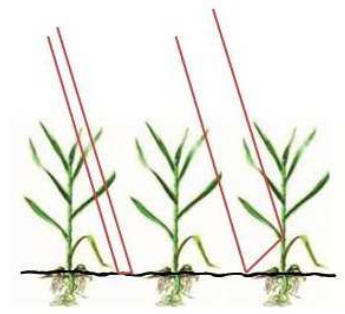

(a) Low Incidence Angle

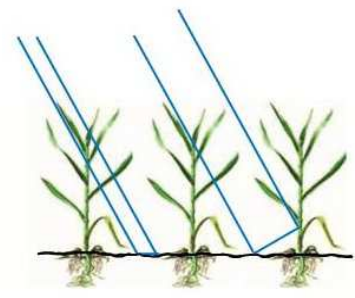

(b) Moderate Incidence Angle

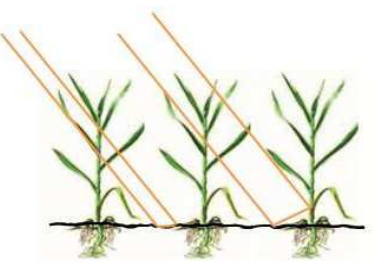

(c) High Incidence Angle

Fig. 2: Microwave signal interaction with agriculture target at various incidence angles

3) Polarization: The transmitting signal and receiving signal polarizations plays a vital role in enhancing the sensitivity of the return signal for a specific application. The two linear orthogonal polarized signals, commonly using horizontal and vertical, can analyze the arbitrarily polarized return signal from the target [35]. It has been observed that the cross-polarized data ( $\mathrm{HV} \& \mathrm{VH}$ ) is more sensitive to crop characteristics than the co-polarized data ( $\mathrm{HH} \& \mathrm{VV}$ ) [36]. Although researchers around the world have been successfully utilized the SAR data acquired by transmitting linear polarized signal for several crop studies, it has few limitations like large power requirement, Faraday rotation effect, and availability of data over restricted swaths [37][38]. Hybrid-polarity SAR architecture, which involves transmitting circular and receives coherent orthogonal linear polarizations, designed to resolve the issues in linear-polarity [39]. After the launch of RISAT-1 with onboard hybridpolarity SAR architecture in 2012, intensive research has been carrying to evaluate the potentials of hybrid polarimetric SAR data for various remote sensing applications [40]. A schematic diagram of linear horizontal, linear vertical, right circular and left circularly polarized signals are given in the Fig. 3.

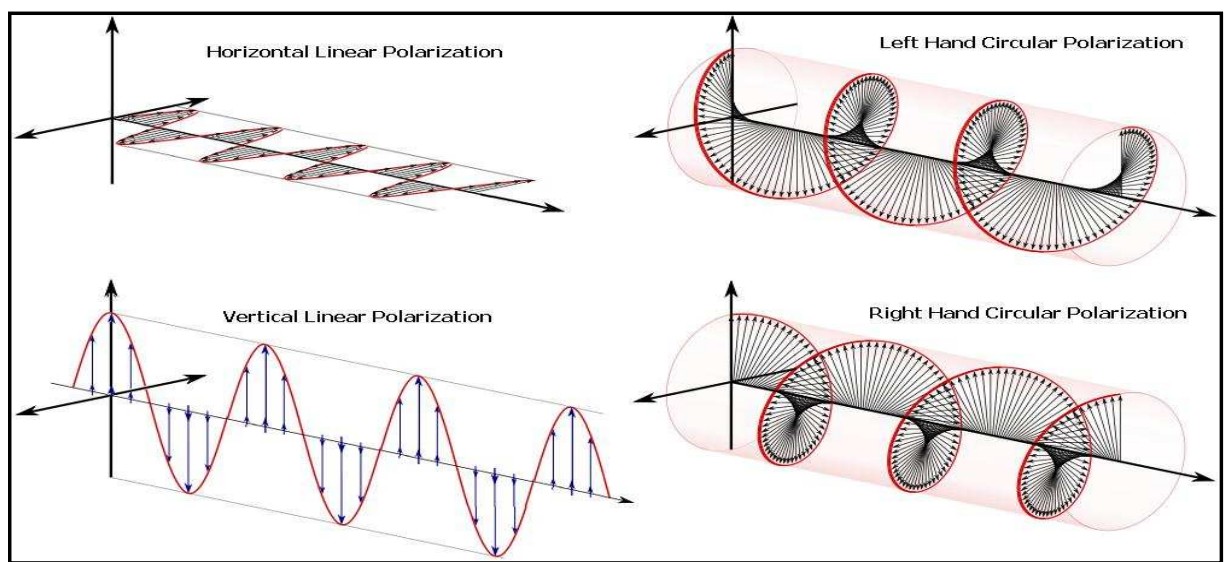

Fig. 3: Schematic diagram of linear horizontal, linear vertical, right circular and left circularly polarized signals [Source: arnoldsat.com]

\section{MATERIALS AND METHODS}

SAR techniques such as backscattering coefficient, SAR polarimetry, SAR interferometry and polarimetric SAR interferometry, have been developed to retrieve the target information from SAR data. Each technique has its advantages and limitations in agricultural crop studies. The basic principles of each technique are given in the following 
for better understanding the purpose of selection of a technique for specific application.

\section{A. Backscattering coefficient}

The backscatter value represents the intensity of the returned signal from the target, which depends on the target characteristics. For any SAR data-based analysis, the raw SAR data which is in digital number (DN) form has to convert into backscattering coefficients, this process called it as radiometric calibration. The main advantage of doing this process is the methodologies developed over calibrated SAR data acquired from one sensor can easily apply over calibrated SAR data acquired from another sensor [41]-[42]. From the first operational spaceborne SAR sensor onboard ERS-1 to the recently launched Sentinel-1 including RISAT1 , researchers had done an extensive research to develop methodologies for SAR sensor calibration [43]-[45]. Several studies had successfully carried over backscatter signatures extracted from SAR data to retrieve agricultural crop biophysical parameters and crop monitoring applications [46]-[47]. Although an increasing trend of backscattering coefficient with crop growth has been observed from ground-based scatterometer and airborne SAR data, Spaceborne SAR data has shown an increasing trend in most of the cases along with decreasing trend in some cases. Srivastava et al., [48] observed the decreasing trend of RH and RV backscatter acquired in the FRS-1 mode of RISAT- 1 with wheat crop growth. The cause of this uncertainty in the space-borne SAR backscatter trend with crop growth needs extensive research.

\section{B. SAR Polarimetry}

The radar return signal polarization from an agricultural target depends on the crop properties like moisture, density, canopy structure, etc. and underneath soil moisture. In linear SAR polarimetry, all four possible linear polarization combinations (viz. HH, HV, VH, and VV) with magnitude and phase information of return signal used to capture, which gives more information than single and dual polarized SAR data. Several decomposition techniques were developed to estimate the scattering mechanisms (even bounce, odd bounce and volume component) based on the covariance and coherence matrices derived from polarimetric SAR data. The coherent decomposition is only useful to study the pure targets and cannot apply for natural targets. The incoherent decomposition is more precise to study the agricultural targets, and its proportion of scattering mechanisms gives the information about the canopy structure, orientation, and moisture of the plants [49]. Yamaguchi et al., [50] have proposed a methodology to retrieve the scattering mechanisms including helix scattering to the basic scattering mechanisms, which observes only from the built-up areas. Despite the advantages of linear polarimetry for agricultural applications, it has few limitations. The recent advancements of SAR polarimetry are compact polarimetry, in which the transmitted signal polarization is a function of linear horizontal and vertical polarizations. Compact polarimetry has been used for several remote sensing applications and observed its potentials to some extent of full polarimetry. The three common modes of the compact polarimetry are $\pi / 4$ mode [51] (transmits $\pm 45^{\circ}$ linear polarization and receives $H \& V$ ), hybrid or $\pi / 2$ mode [39] (transmits circular polarization and receives $\mathrm{H} \& \mathrm{~V}$ ) and CC mode [52] (transmits circular polarization and receives left and right circular polarization). Raney et al., [39, 53] proposed $\mathrm{m}-\delta$ and $\mathrm{m}-\chi$ space decomposition techniques to retrieve basic scattering mechanisms from hybrid polarimetric SAR data. Numerous researchers have adopted the radiative transfer theorems using scattering decompositions to retrieve biophysical parameters of agricultural crop. Some of the findings in agricultural crop studies using SAR polarimetry are given in Table 3.

\section{SAR Interferometry}

In SAR interferometric technique, normalized crosscorrelation of two complex signals received in two different passes over the study area was used for earth's surface studies (given in Equation 2). The interferometric coherence is always high for the stable features like settlements and low for the unstable features like surface water. In the beginning, this technique was widely used for surface movement studies and digital elevation model generation [54]. Numerous researchers have demonstrated the potential of SAR interferometry for various remote sensing applications like plant density mapping, plant height estimation, surface water extent in adverse weather conditions and detection of human settlements, etc. A few important findings of using SAR interferometry for agricultural crop studies are given in Table 3. This technique is identified both theoretically and experimentally as highly reliable for crop height estimation.

$$
\gamma=\frac{\left.\mid s_{1} s_{2}\right\}}{\sqrt{d s_{2} s_{1} S_{2} s_{2} s^{2}}}
$$

Where * represents a complex conjugate

\section{Polarimetric SAR Interferometry}

Polarimetric SAR Interferometry technique uses fully polarimetric SAR data acquired in two passes over the study area. Polarimetric SAR data is sensitive to geometrical and electrical properties of the scattering elements and allows the identification and separation of scattering mechanisms of natural media. On the other hand, SAR interferometric data are highly sensitive to the vertical structure parameters distributed spatially. In polarimetric SAR interferometry technique uses the both polarimetric and interferometry concept to provide the sensitivity to the vertical distribution of scattering mechanisms. The synergic use of SAR polarimetric and SAR interferometry can enhance the application potential of SAR data [55]. So far, fully polarimetric SAR interferometric has been intensively studied for earth observation applications. Whereas, limited research has been carried using compact polarimetric SAR interferometry [56] in the retrieval of agricultural crop biophysical parameters. The lack of operationally available of SAR sensors providing polarimetric SAR interferometry data makes it difficult to carry research on this technique. A list of some research works made efforts to retrieve biophysical vegetation parameters using polarimetric SAR interferometry technique are given in Table 3 . 


\section{RESULTS AND DISCUSSION}

Radar remote sensing data has been largely used for agricultural crop characteristics studies in both qualitative and quantitative analysis perspective. An understanding of the physical and dielectric properties of plants and their interaction with different combinations of SAR sensor parameters is needed for SAR data analysis. Both the theory and technological tools for radar remote sensing have been developed for a wide range of agricultural applications.

\section{A. Crop inventory and Average estimation}

Crop inventory and acreage estimation is the primary step for any development and management of crop monitoring systems [57]. Crop discrimination based on radar remote sensing data is grounded with the concept that each crop has its unique influence on the illuminated microwave signal depends on its growth stage and condition of the crop [58]. McNairn et al., [59] observed that L-band data is more suitable to discriminate the larger biomass crops and C-band for low biomass crops. It has been observed that the multitemporal SAR data is more suitable for crop discrimination than the single date SAR data [60]. The color composite image using multi-temporal RADARSAT SAR data over parts of Bhardaman district, West Bengal, India, which is dominated with Paddy fields, is given in Figure 4 along with the derived Paddy crop map. However, it has been suggested that the use of multipolarized and multitemporal SAR data in order to improve the overall agricultural crop classification accuracy. Since polarimetric SAR data has a wide range of information than the polarized
SAR data, investigators made efforts to develop methodologies using polarimetric SAR data for crop mapping [61]-[62]. It was reported by Lee et al., [61] that the phase difference between the VV and $\mathrm{HH}$ polarization is an essential factor for crop classification than the crosspolarization due to its high correlation.

In contrast to statistical based classification techniques, the need for machine learning based classification techniques is observed to improve the accuracy due to its high influence of speckle noise. Zhang and $\mathrm{Wu}$ [63], had proposed a methodology for crop classification by using forward neural network with adaptive chaotic particle swarm optimization (ACPSO). The results of this study showed the better performance of ACPSO than back-propagation (BP), adaptive $\mathrm{BP}$, momentum $\mathrm{BP}$, particle swarm optimization, and resilient back-propagation methods. Researchers have also made attempts to delineate the flooded agricultural fields. Patel and Panigrahy, [64] have delineated the rice fields affected by flash flood using RADARSAT SAR data, based on the significant backscatter difference between flooded and normal fields. The observed variation of backscatter from normal and flood receded rice fields is given in Figure 5. One of the current active researches is an investigation on potentials of hybrid polarimetric SAR data for crop discrimination applications. Uppala et al., [65] had analyzed the single date RISAT- 1 hybrid polarimetric SAR data for rice crop discrimination by subjecting to $\mathrm{m}-\delta, \mathrm{m}-\chi$ space decompositions and supervised classification. Sivasankar et al., [66] investigated the hybrid polarimetric decomposition techniques include $\mathrm{m}-\delta, \mathrm{m}-\chi$ and $\mathrm{m}-\psi$ for crop discrimination.

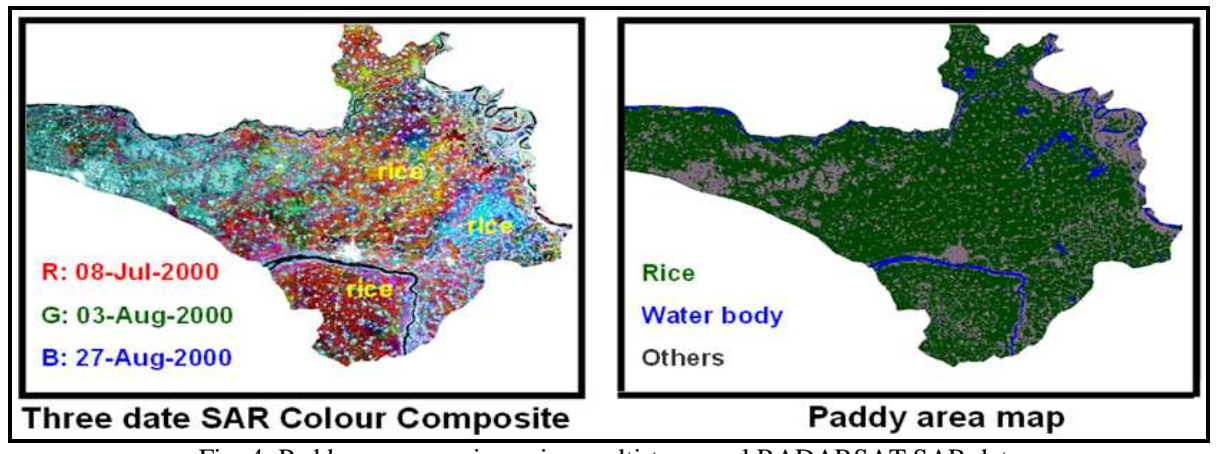

Fig. 4: Paddy crop mapping using multi-temporal RADARSAT SAR data

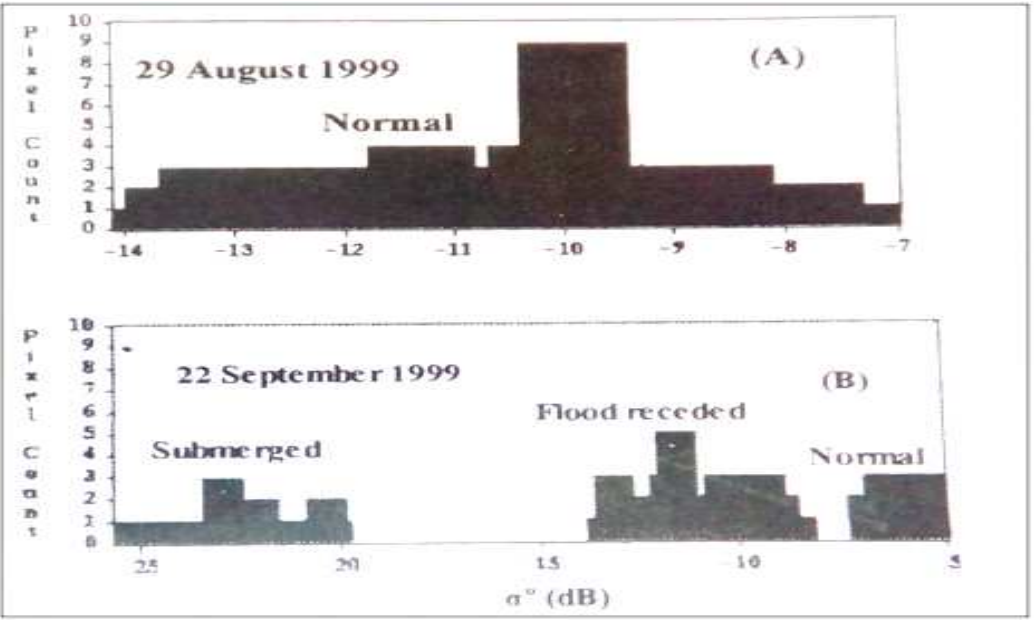


Fig. 5: The backscatter characteristics generated from normal, submerged and partially flooded fields before and after the flash flood (A) Aug 29, 1999, and (B) Sep 22, 1999

\section{B. Leaf Area Index}

Leaf area index (LAI) is defined as the ratio of one-sided green leaf area to unit ground surface area. Solar radiation is the basic source of energy for plants in the photosynthesis process, is a major regulator of crop yield. The amount of solar energy receiving by the plant is a function of leaf area exposed to sunlight. Because of this, knowledge of LAI during the complete crop cycle is required to understand the crop growth process and to estimate the crop yield [67]. In this context, researchers have studied the sensitivity of backscattering coefficients of $\mathrm{P}, \mathrm{L}, \mathrm{C}, \mathrm{X}$ bands towards the leaf area index of broadleaf and narrow leaf crops [20, 6869]. These studies have concluded that the P- \& L-band is useful for broadleaf crops and C- \& X-bands for small leaf crops. Ulaby et al., [6] had related the backscattering coefficients to the LAI and also developed two models, one for corn and sorghum and another for the wheat crop, by extending the water cloud model of Attema and Ulaby [70]. This study was concluded that the backscattering coefficients during the early stage of growth, soil contribution may be very high, and for end-period before harvest, the contribution of soil and stalks are important for sorghum and corn, whereas the heads and soil for the wheat crop. In another study, Shao et al., [71] successfully employed Michigan Microwave Canopy Scattering model to estimate LAI of rice using Envisat ASAR data.

On the other side, several research works have been carried out using empirical and semi-empirical based models to retrieve the LAI. Paloscia [69], related the backscattering coefficients at P-, L- and C-bands with the volumetric leaf area index (i.e., the leaf area index multiplied by the average leaf thickness) normalized to the wave number for various crops including alfalfa, wheat, meadows, sorghum, corn, sunflower, and vineyard. Fontanelli et al., [68] analyzed the sensitivity of X-band SAR data towards LAI of wheat and barley crops. It was observed that the sensitivity to the LAI for both the crops at almost senescent phase was not significant since the backscatter is mainly related to the water content present in the plants, which considerably decrease in the ripening phase. It is well known that the radar backscatter response from agricultural fields is a complex function of several crop biophysical parameters and
SAR sensor parameters. Since the machine learning techniques can resolve the complex relationships, in recent past researchers are putting efforts to retrieve LAI and other crop biophysical parameters using machine learning techniques.

\section{Fresh Biomass}

Discriminating among the crop species and retrieving the biomass are among the primary objectives of the radar vegetation studies. Fresh biomass primarily refers to the fresh weight of the amount of biological or organic matter that can derive from a living organism and is an essential factor for the plant growth analysis. Several studies with the ground-based and spaceborne active satellite sensors have provided insight and understanding in the estimation of fresh biomass. The backscattering coefficients as well as polarimetric parameters have been shown to be sensitive to the crop biomass and can be affected by the shape and dimensions of plant constituents [72]-[74]. Wu et al., [75] analyzed the quad-polarized time series RADARSAT-2 data and found that the temporal signature of fresh biomass for the Paddy crop showed a good correlation with the backscattering coefficient $\left(\sigma^{\circ}\right)$ in $\mathrm{HV} / \mathrm{HH}$ polarization, with the $\mathrm{R}^{2}$ greater than 0.8 , while the correlation with the individual $\mathrm{HH}$ and $\mathrm{HV}$ channels was lower than 0.6. In a similar study, Blaes et al., [76] found VV/VH polarization ratio computed at a high incidence angle of $45^{\circ}$, to be the suitable index for the maize crop growth assessment till the fresh biomass of $6.5 \mathrm{~kg} / \mathrm{m}^{2}$. Patel and Srivastava [74], developed the fresh biomass retrieval models for Mustard and Wheat crop using the stepwise regression approach. The sensitivity of the logarithmically transformed biomass was analyzed concerning the full and simulated hybrid polarimetric RADARSAT-2 data as well as the backscatter data alone. The analysis revealed the parameters derived from the fully polarimetric data had the highest correlation with the wheat and mustard crop fresh biomass $\left(\mathrm{R}^{2}\right.$ of 0.85 and 0.77 , respectively) followed by the hybrid polarimetric data $\left(\mathrm{R}^{2}\right.$ of 0.74 and 0.53 , respectively). The scatter plot of observed and estimated values of fresh biomass for wheat and mustard is given in Fig. 6.

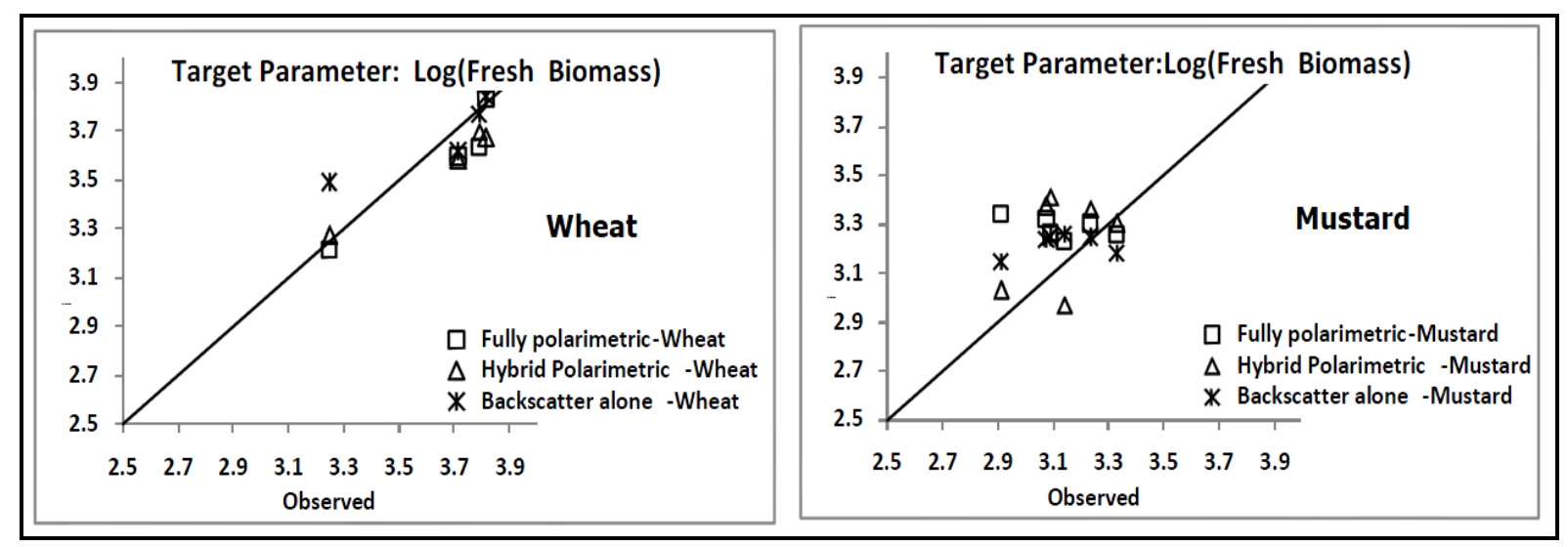

Fig. 6: Observed vs. Estimated for fresh biomass for Wheat and Mustard using fully polarimetric, Hybrid polarimetric and only SAR backscatter; The line shown is 1-1 line 
In another study, Jia et al., [77] utilized the artificial neural network algorithm to invert the biomass of Paddy fields from the quad-polarized RADARSAT-2 datasets. The network trained with the backscattering data simulated using the Monte Carlo simulation model gave the accuracy as high as 0.989 and RMSE of $0.477 \mathrm{~kg} / \mathrm{m}^{2}$ when the inverted biomass was compared to the measured biomass values. Macelloni et al., [20] utilized the multi-frequency, multitemporal polarimetric data at C- and L-bands and found that the crop $\sigma^{\circ}$ and biomass depend upon the plant type, and the trend may be different for the narrow and broadleaf crops. In the latter case, the $\sigma^{\circ}$ was found to increase with the biomass values, especially at L-band while in case of narrow leaf crops, the trend was flat or decreasing, denoting the prevalent effect of scattering and absorption in the two respective categories. The correlation analysis revealed that the LAI could be used as an indicator of the fresh biomass since both were correlated with the $\mathrm{R}^{2}$ of 0.81 . Mattia et al., [78] studied the sensitivity of the L-band backscatter to the soil moisture and fresh biomass of wheat crop and found that at $\mathrm{HH}$ polarization, the interaction with the crop canopy was almost negligible, which consequently resulted in no correlation between the $\mathrm{HH}$ backscattering and fresh biomass.

\section{Plant height}

Plant height is one of the important parameters to indicate the growth stage of a crop. At present, there are two broad categories to retrieve plant height from SAR data. The first category makes use of backscattering coefficients, where relates the intensity of the backscattered signal with plant height. Some studies have provided useful methodologies to retrieve plant height from backscattering coefficients generated from SAR data [73], [79]. Chakraborty et al., [33] analyzed the sensitivity of backscatter towards rice crop height using multi-temporal, multi-incidence angle RADARSAT Standard beam SAR data. This analysis was found that the high incidence angle data $\left(>40^{\circ}\right)$ is better correlated to crop height than the low incidence angle data. The developed model based on inversion algorithm retrieved the crop height with $90 \%$ overall accuracy. However, it was found that the intensity of the backscattered signal is more sensitive towards plant water content, biomass and LAI than plant height [48].

On the other hand, researchers have identified the phase information from two different passes is more preferable for crop height estimation than the backscattering coefficients. Srivastava et al., [55] have attempted to evaluate the application potential of SAR interferometry for land-cover mapping and crop height estimation using ERS-1/ERS-2 Tandem pair data. This study has concluded that the SAR interferometry is preferable for surface water extension mapping in typical situations like wind-induced rough water surface than from backscatter image. The empirical relationship developed between wheat crop height and interferometric coherence, given in Fig. 7, yielded the correlation coefficient of 0.74 and 0.05 level of significance. It is well known that synergic use of signal intensity (backscattering coefficient) and interferometric coherence can improve the accuracy. In this context, Ballester-Berman et al., [80] had developed a retrieval algorithm by adopting a two-layer model developed by Cloude and Papathanassiou [81], which was made for forest height estimation, for vertically oriented crops based on polarimetric SAR interferometry. The proposed algorithm was validated experimentally with indoor wide-band polarimetric measurements on corn and rice fields, and it observed that the algorithm performs well only for the coherence of the above 0.3 samples.

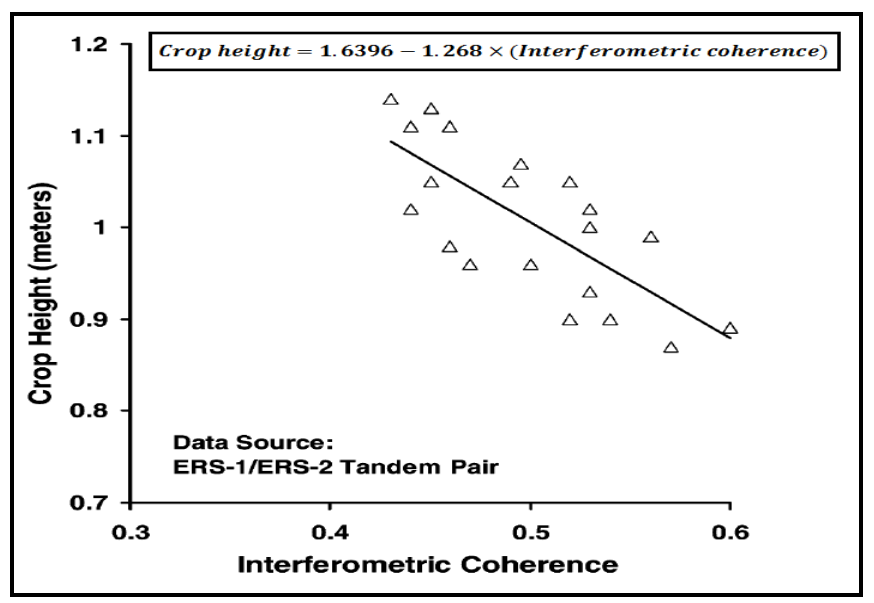

Fig. 7: Variation of interferometric coherence with a height of the wheat crop

\section{E. Crop yield}

The crop yield is a function of several variables, including soil moisture, soil fertility, weather conditions and health of the plants during the crop growing season [82]-[83]. During the 1980's, the yield was predicted based on the past years' yield scenario and the current weather conditions [84]. The yield prediction can be significantly improved by including the knowledge of field level soil moisture and plant health status during the growing season [85]-[86]. It has been identified that LAI, fresh biomass, plant water content, and height indicates the plant health status. Remote sensing has become the primary source to monitor the field level crop biophysical parameters, which intern improves the yield prediction. Setiyono et al., [87] estimated the rice yield based on Crop Growth Simulation Model (CGSM) of Oryza2000 [88]. Plant health status has been indicated with LAI and retrieved from the radar backscatter of ASAR WS data. To minimize the complexity of these models, researchers were also made attempts to estimate yield using an empirical approach [89]. Patel et al., [90] has conceptualized Interaction Factor (IF) by using volume, height, moisture for each of the components and density of plant, to exploit the unique interaction of cross-polarized SAR with the wheat crop. The proposed $I_{\text {Head }} h_{\text {ead }}$ is given in the Equation 3, and the relationship between $\mathrm{IF}_{\text {Head }}$ and number of grains (Yield) is given in Figure 8. The shallow incidence angle cross-polarized C-band SAR backscatter is also related with $\mathrm{IF}_{\text {Head }}$ using step-wise regression, which is given $\mathrm{R}^{2}$ of 0.78 with $125.83 \mathrm{~F}$ value.

$$
I F_{\text {yend }}=\text { Moist comient of head } * \text { Vol of had } * \frac{\text { plants density }}{\text { height of hecd }}
$$




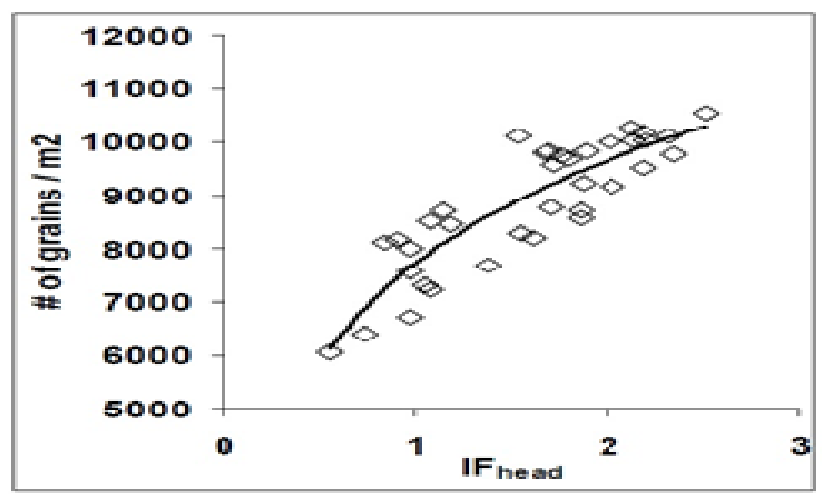

Fig. 8: Variation of number of wheat grains per square meter with IF of wheat head

TABLE III

A LIST OF FEW IMPORTANT RESEARCH WORKS USED RADAR REMOTE SENSING FOR AGRICULTURAL APPLICATIONS

\begin{tabular}{|c|c|c|c|c|c|c|c|c|c|}
\hline \multirow[b]{2}{*}{ Author/s } & \multirow[b]{2}{*}{$\begin{array}{l}\text { SAR } \\
\text { Technique }\end{array}$} & \multirow{2}{*}{$\begin{array}{l}\text { Sensor Parameters } \\
\text { Frequency }\end{array}$} & \multicolumn{7}{|c|}{$\begin{array}{l}\text { Agricultural Crop Biophysical } \\
\text { Parameters }\end{array}$} \\
\hline & & & 录 & $\stackrel{\mathscr{E}}{\tilde{E}}$ & 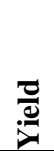 & 营 & 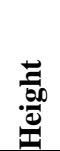 & 离 & 递 \\
\hline Ballester-Berman et al., [80] & Pol. SAR Inter. & $\mathrm{S}, \mathrm{C}$ and $\mathrm{X}$ bands & & & & & $\sqrt{ }$ & & \\
\hline Ulaby et al., [6] & Backscatter coefficient & $\mathrm{X}, \mathrm{Ku}$ and $\mathrm{Ka}$ bands & $\sqrt{ }$ & & & & & & \\
\hline Ulaby et al., [91] & Backscatter coefficient & $\mathrm{C}$ and $\mathrm{L}$ bands & & $\sqrt{ }$ & & & & & \\
\hline Moran et al., [92] & Backscatter coefficient & C-band & & $\sqrt{ }$ & & & & & $\sqrt{ }$ \\
\hline Wu et al., [93] & Backscatter coefficient & C-band & & $\sqrt{ }$ & & & $\sqrt{ }$ & & \\
\hline Paloscia et al., [94] & Backscatter coefficient & $\mathrm{L}$ and $\mathrm{X}$ bands & & $\sqrt{ }$ & & & & & \\
\hline Jang et al., [95] & Backscatter coefficient & C-band & & & & & & & $\sqrt{ }$ \\
\hline Kim et al., [96] & Backscatter coefficient & $\mathrm{X}, \mathrm{C}$ and $\mathrm{L}$ bands & & & & & & $\sqrt{ }$ & \\
\hline Inoue and Sakaiya [97] & Backscatter coefficient & X-band & $\sqrt{ }$ & $\sqrt{ }$ & & & & & \\
\hline Fontanelli et al., [68] & Backscatter coefficient & X-band & $\sqrt{ }$ & & & & & & \\
\hline Emmerik et al., [98] & Backscatter coefficient & $\mathrm{L}, \mathrm{X}, \mathrm{C}$ and $\mathrm{Ku}$ bands & & & & & & $\sqrt{ }$ & \\
\hline Uppala et al., [65] & Polarimetric SAR & C-band & & & & & & & $\sqrt{ }$ \\
\hline Haldar et al., [79] & Polarimetric SAR & C-band & & $\sqrt{ }$ & & & $\sqrt{ }$ & & \\
\hline Srivastava et al., [55] & SAR Interferometry & C-band & & & & & $\sqrt{ }$ & & \\
\hline Patel et al., [17] & Backscatter coefficient & $\mathrm{C}$ and $\mathrm{L}$ band & & & & $\sqrt{ }$ & & & \\
\hline Patel et al., [90] & Backscatter coefficient & C-band & & & $\sqrt{ }$ & & & & \\
\hline Patel and Srivastava [74] & Polarimetric SAR & C-band & & $\sqrt{ }$ & & & & $\sqrt{ }$ & \\
\hline Tan et al., [99] & Polarimetric SAR & L-band & & & & & & & $\sqrt{ }$ \\
\hline Lopez-Sanchez et al., [100] & Pol. SAR Inter. & $\mathrm{S}, \mathrm{C}$ and $\mathrm{X}$ bands & & & & & $\sqrt{ }$ & & \\
\hline Engdahl [101] & SAR Interferometry & C-band & & & & & & & $\sqrt{ }$ \\
\hline Srivastava et al., [48] & Polarimetric SAR & C-band & $\sqrt{ }$ & $\sqrt{ }$ & & & $\sqrt{ }$ & $\sqrt{ }$ & \\
\hline Erten et al., [102] & $\begin{array}{l}\text { Backscatter coefficient, } \\
\text { SAR Interferometry, and } \\
\text { Pol. SAR Inter. }\end{array}$ & X-band & & & & & $\sqrt{ }$ & & \\
\hline
\end{tabular}

\section{CONCLUSIONS}

Since, electromagnetic signals in visible and infrared region cannot penetrate through clouds, limits the optical remote sensing data for operational use of agricultural crop studies like biomass, crop water content, stem volume, leaf area index (LAI) and plant height etc., which is a highly variable phenomenon in both spatial and temporal. Remote sensing data acquired in microwave region has the edge over all other remote sensing techniques for the agricultural crop studies due to its all-weather capability and unique sensitivity to geometrical, physical and dielectric properties of various components of the crop. We reviewed the potential of SAR data for agricultural crop studies using backscattering coefficients, polarimetric SAR, SAR interferometry and polarimetric SAR interferometry. It is observed that earlier researchers were used backscattering coefficients of single, dual polarized SAR data but the accuracy was limited due to the difficulty to distinguish the return signal from various components of vegetation. Later quad (entirely) linear polarimetric data has been used, with which the return signal energy can be distinguished from various components of the crop using several scattering decomposition techniques. Where volume component indicates the return signal from vegetation canopy, even bounce indicates the return signal from ground-stem or stemground interaction and odd bounce indicates the return signal from the ground. Recent advances of hybrid polarimetry are 
having advantages over linear polarimetry like low susceptibility to noise, self-calibration, higher incident angle range coverage, more considerable swath coverage. After the launch of RISAT-1 with hybrid polarimetry architecture, researchers are showing great interest to study the vegetation biophysical parameters using hybrid polarimetric SAR data. Interferometry can better estimate vegetation height than using backscatter and SAR polarimetry. Moreover, polarimetric SAR interferometry gives more information than SAR polarimetry and SAR interferometry alone but the lack of operational sensor limits this technique for operational use.

This study proposed three types of modeling algorithms have been commonly used to study the agricultural crop characteristics. Empirical-based: This technique is relatively easy to develop the model, but these are vegetation type and stage dependent. Machine Learning based: This technique is the best suited to understand the relationship between vegetation biophysical parameters and SAR data. However, it requires a significant amount of in-situ data along with SAR data for an accurate and precise agricultural crop information retrieval. Radiative Transfer Theory based technique gives more accurate irrespective of crop type and stage independent. However, the models require auxiliary data of the crop or/and soil which is a spatially and temporally changing phenomenon. So, it is necessary to progress the research in such a way to develop more precise crop biophysical parameters retrieval algorithms which intern can help to predict the yield from field level.

\section{REFERENCES}

[1] D. Tilman, J. Fargione, B. Wolff, C. D'Antonio, A. Dobson, R. Howarth, D. Schindler, W. Schlesinger, D. Simberloff, and D. Swackhamer, "Forecasting agriculturally driven global environmental change," Science, vol. 292, No. 5515, pp. 281-284, 2011.

[2] B. Brisco, R. J. Brown, T. Hirose, H. McNairn, and K. Staenz, "Precision agriculture and the role of remote sensing: A review," Canadian Journal of Remote Sensing, vol. 24, no. 3, pp. 315-327, 1998.

[3] B. Basso, D. Cammarano, and E. Carfagna, "Review of crop yield forecasting methods and early warning systems," Report presented to First Meeting of the Scientific Advisory Committee of the Global Strategy to Improve Agriculture and Rural Statistics FAO, Headquarters, Rome, Italy. pp. 1-56, 2013.

[4] P. C. Doraiswamy, S. Moulin, P. W. Cook, and A. Stern, "Crop yield assessment from remote sensing," Photogrammetric Engineering \& Remote Sensing, vol. 69, no. 6, pp. 665-674, 2003.

[5] J. C. Shi, Y. Du, J. Y. Du, L. M. Jiang, L. N. Chai, K. B. Mao, P. Xu, W. J. Ni, C. Xiong, Q. Liu, C. Z. Liu, P. Guo, Q. Cui, Y. Q. Li, J. Chen, A. Q. Wang, H. J. Luo, and Y. H. Wang, "Progresses on microwave remote sensing of land surface parameters," Science China Earth Sciences, vol. 55, no. 7, pp. 1052-1078, 2012.

[6] F. T. Ulaby, C. T. Allen, G. Eger, and E. Kanemasu, "Relating the microwave backscattering coefficient to leaf area index," Remote Sensing of Environment, vol. 14, pp. 113-133, 1984.

[7] H. S. Srivastava, P. Patel, K. P. Sharma, Y. V. N. Krishnamurthy, and V. Dadhwal, "A semi-empirical modeling approach to calculate two-way attenuation in radar backscattering from soil due to crop cover," Current Science, vol. 100, no. 12, pp. 1871-1874, 2011.

[8] J. D. Ballester-Berman, and J. M. Lopez-Sanchez, "Time series of hybrid-polarity parameters over agricultural crops," IEEE Geoscience and Remote Sensing Letters, vol. 9, no. 1, pp. 139-143, 2012.

[9] W. M. Boerner, H. Mott, and E. Luneburg, "Polarimetry in remote sensing: basic and applied concepts," IEEE Transactions on Geoscience and Remote Sensing, vol. 3, pp. 1401-1403, 1997.
[10] R. Bamler, and P. Hartl, "Synthetic aperture radar interferometry," Inverse Problems, vol. 14, pp. R1-R54, 1998.

[11] S. R. Cloude, and K. P. Papathanassiou, "Polarimetric SAR Interferometry," IEEE Transactions on Geoscience and Remote Sensing, vol. 36, no. 5, pp. 1551-1565, 1998.

[12] H. S. Srivastava, P. Patel, Y. Sharma, and R. R. Navalgund, "Largearea soil moisture estimation using multi-incidence angle RADARSAT-1 SAR data," IEEE Transactions on Geoscience and Remote Sensing, vol. 47, no. 8, pp. 2528-2535, 2009.

[13] J. M. Lopez-Sanchez, I. Hajnsek, and J. D. Ballester-Berman, "First demonstration of agriculture height retrieval with PolInSAR airborne data," IEEE Transactions on Geoscience and Remote Sensing. vol. 9, no. 2, pp. 242-246, 2012.

[14] N. Baghdadi, M. Bernier, R. Gauthier, and I. Neeson, "Evaluation of C-band SAR data for wetlands mapping," International Journal of Remote Sensing, vol. 22, no. 1, pp. 71-88, 2001.

[15] H. S. Srivastava, P. Patel, K. P. Sharma, and Y. V. N. Krishnamurthy, "Explored and demonstrated potential applications of multiparameteric synthetic aperture radar in wetland studies in context of Keoladeo national park, Bharatpur, India," in Proc. of 2nd Annual Research Seminar on Keoladeo National Park, Keoladeo National Park, Bharatpur, India, pp. 1-30, 2009.

[16] H. S. Srivastava, P. Patel, S. N. Prasad, Y. Sharma, B. A. Khan, B. Praveen, K. C. A. Arun Prasad, S. Sharma, L. Vijayan, and V. S. Vijayan, "Potential applications of multi-parametric synthetic aperture radar (SAR) data in wetland inventory: A case study of Keoladeo national park (A world heritage and Ramsar site), Bharatpur, India," in Proc. of Taal 2007: The 12th World Lake Conference, pp. 1862-1879, 2008.

[17] P. Patel, H. S. Srivastava, S. Panigrahy, and J. S. Parihar, "Comparative evaluation of the sensitivity of multi-polarized multifrequency SAR backscatter to plant density," International Journal of Remote Sensing, vol. 27, no. 2, pp. 293-305, 2006.

[18] M. C. Dobson, F. T. Ulaby, L. E. Pierce, T. L. Sharik, K. M. Bergen, J. Kellndorfer, J. R. Kendra, E. Li, and Y. C. Lin, "Estimation of forest biophysical characteristics in Northern Michigan with SIRC/X-SAR," IEEE Transactions on Geoscience and Remote Sensing, vol. 33, no. 4, pp. 877-895, 1995.

[19] J. M. Lone, T. Sivasankar, K. K. Sarma, A. Qadir, and P. L. N. Raju, "Influence of slope aspect on above ground biomass estimation using ALOS-2 data," International Journal of Science and Research, vol. 6, no. 6, pp. 1422-1428, 2017.

[20] G. Macelloni, S. Paloscia, P. Pampaloni, F. Marliani, and M. Gai, "The Relationship between the backscattering coefficient and the biomass of narrow and broad leaf crops," IEEE Transactions on Geoscience and Remote Sensing, vol. 39, no. 4, pp. 873-884, 2001.

[21] P. Patel, H. S. Srivastava, and R. R. Navalgund, "Use of synthetic aperture radar polarimetry to characterize wetland targets of Keoladeo National Park, Bharatpur, India," Current Science, vol. 97, no. 4, pp. 529-537, 2009.

[22] H. S. Srivastava, P. K. Sharma, D. Kumar, T. Sivasankar, R. S. Mishra, M. Mishra, and P. Patel, "Soil moisture variation over parts of Saharanpur and Haridwar districts (India) during November-2006 to June-2007 as observed by multi-polarized (VV/HH \& VV/VH) ENVISAT-1 temporal ASAR data," International Journal of Advanced Engineering Research and Science, vol. 2, no. 1, pp. 31-39, 2015.

[23] M. S. Moran, A. Vidal, D. Troufleau, J. Qi, T. R. Clarke, P. J. Pinter Jr., T. A. Mitchell, Y. Inoue, and C. M. U. Neale, "Combining multifrequency microwave and optical data for crop management," Remote Sensing of Environment, vol. 61, no. 1, pp. 96-109, 1997.

[24] H. S. Srivastava, "Interaction of multi-frequency multi-polarized DLR ESAR data with various targets: A case study with $\mathrm{C}, \mathrm{L}$ and $\mathrm{P}$ bands acquired at all the four linear ( $\mathrm{VV}, \mathrm{HH}, \mathrm{VH}$ and $\mathrm{HV}$ ) polarizations," JEP-MW Conference, Space Applications Centre, Ahmedabad, India. 2007.

[25] P. Patel, and H. S. Srivastava, "Ground truth planning for Synthetic Aperture Radar (SAR): Addressing various challenges using statistical approach," International Journal of Advancement in Remote Sensing, GIS and Geography, vol. 1, no. 2, pp. 1-17, 2013.

[26] N. Baghdadi, N. Boyer, P. Todoroff, M. E. Hajj, and A. Begue, "Potential of SAR sensors TerraSAR-X, ASAR/ENISAT and PALSAR/ALOS for monitoring sugarcane crops on Reunion Island," Remote Sensing of Environment, vol. 113, pp. 1724-1738, 2009.

[27] F. T. Ulaby, and E. Wilson, "Microwave attenuation properties of vegetation canopies," IEEE Transactions on Geoscience and Remote Sensing, vol. GE-23, no. 5, pp. 746-753, 1985, 1985. 
[28] A. Balenzano, F. Mattia, G. Satalino, and M. W. J. Davidson, "Dense temporal series of C- and L-band SAR data for soil moisture retrieval over agricultural crops," IEEE Journal of Selected Topics in Applied Earth Observations and Remote Sensing, vol. 4, no. 2, pp. 439-450, 2011.

[29] M. C. Dobson, F. T. Ulaby, T. Le Toan, A. Beaudoin, E. S. Kasischke, and N. L. Christensen, "Dependence of radar backscatter on conifer forest biomass," IEEE Transactions on Geoscience and Remote Sensing, vol. 30, pp. 412-415, 1992.

[30] H. S. Srivastava, P. Patel, and R. R. Navalgund, "How far SAR has fulfilled its expectation for soil moisture retrieval?," Microwave Remote Sensing of the Atmosphere and Environment V, Proc. of SPIE, vol. 6410, no. 641001, pp. 1-12, 2006.

[31] M. C. Dobson, and F. T. Ulaby, "Active microwave soil moisture research," IEEE Transactions on Geoscience and Remote Sensing, vol. GE-24, no. 1, pp. 23-36, 1986.

[32] S. Panigrahy, K. R. Manjunath, M. Chakraborty, N. Kundu, and J. S Parihar, "Evaluation of RADARSAT standard beam data for identification of potato and rice crops in India," ISPRS Journal of Photogrammetry and Remote Sensing, vol. 54, no. 4, pp. 254-262, 1999.

[33] M. Chakraborty, K. R. Manjunath, S. Panigrahy, N. Kundu, and J. S. Parihar, "Rice crop parameter retrieval using multi-temporal, multiincidence angle Radarsat SAR data," ISPRS Journal of Photogrammetry and Remote Sensing, vol. 59, no. 5, pp. 310-322, 2005.

[34] S. Mohan, P. Patel, D. R. Rajak, H. S. Srivastava, R. L. Mehta, and N. S. Mehta, "Evaluation of multiple incidence angle X-SAR images covering parts of Gujarat for roughness, soil moisture and vegetation studies," Scientific report JPL-NASA, pp. 01-04, 1997. http://southport.jpl.nasa.gov/reports/finrpt/Mohan/mohan.htm

[35] G. G. Stokes, "On the composition and resolution of streams of polarized light from different Sources," Transactions of the Cambridge Philosophical Society, vol. 9, pp. 399-416, 1852.

[36] P. M. Treitz, O. R. Filho, P. J. Howarth, and E. D. Soulis, "Textural processing of multi-polarization SAR for agricultural crop classification," in Proc. of IGARSS '96. Remote Sensing for a Sustainable Future, vol. 4, pp. 1986-1988, 1996.

[37] A. Freeman, and S. S. Saatchi, "On the detection of Faraday rotation in linearly polarized L-band SAR backscatter signatures," IEEE Transactions on Geoscience and Remote Sensing, vol. 42, no. 8, pp. 1607-1616, 2004

[38] V. Turkar, S. De, G. G. Ponnurangam, R. Deo, Y. S. Rao, and A. Das, "Classification of RISAT-1 hybrid polarimetric data for various land features," Synthetic Aperture Radar (APSAR), 2013 Asia-Pacific Conference on (IEEE), Tsukuba, pp. 494-497, 2013.

[39] R. K. Raney, "Hybrid-Polarity SAR Architecture," IEEE Transactions on Geoscience and Remote Sensing, vol. 45, no. 11, pp. 3397-3404, 2007.

[40] M. Chakraborty, S. Panigrahy, A. S. Rajawat, and R. Kumar, "Initial results using RISAT-1 C-band SAR data," Current Science, vol. 104, no. 4, pp. 490-501, 2013.

[41] M. D. Mishra, P. Patel, H. S. Srivastava, P. R. Patel, A. Shukla, and A. K. Shukla, "Absolute radiometric calibration of FRS-1 and MRS mode of RISAT-1 Synthetic Aperture Radar (SAR) data using corner reflectors," International Journal of Advanced Engineering Research and Science, vol. 1, no. 6, pp. 78-89, 2014.

[42] P. Patel, H. S. Srivastava, M. D. Mishra, P. R. Patel, A. Shukla, R. P. Prajapati, and A. K. Shukla, "Calibration of RISAT-1 Fine Resolution (FRS-1) mode data processed before implementation of DP software update version-1.3.00," Scientific Report, SAC/EPSA/ADVG/CVD/CAL-VAL/SR/07/2014, Space Applications Centre (ISRO), Ahmedabad, India. 2014.

[43] S. Mohan, S. K. Basu, A. M. Jha, T. Misra, R. K. Kewalia, K. N. Padia, P. Patel, and H. S. Srivastava, "Calibration of ERS-1 SAR data," Technical Report, SAC/RSA/RSAG/ERS-1/SN/07/95, Indian Space Research Organisation (ISRO), Ahmedabad, India. 1995.

[44] A. P. Luscombe, "RADARSAT-2 SAR image quality and calibration operations," Canadian Journal of Remote Sensing, vol. 30, no. 3, pp. 345-354, 2004

[45] P. Patel, H. S. Srivastava, M. Mishra, P. R. Patel, A. Shukla, A. K. Shukla, and Ajai, "RISAT-1 SAR calibration: Recent results," Scientific Report, SAC/EPSA/MPSG/CVD/CAL-VAL/WP/09/12, Indian Space Research Organisation (ISRO), Ahmedabad, India. 2012.

[46] J. P. Wigneron, P. Ferrrazoli, A. Olioso, P. Bertuzzi, and A. Chanzy, "A simple approach to monitor crop biomass from $\mathrm{C}$-band radar data," Remote Sensing of Environment, vol. 69, no. 2, pp. 179-188, 1999.

[47] L. Dente, G. Satalino, F. Mattia, and M. Rinaldi, "Assimilation of leaf area index derived from ASAR and MERIS data into CERESWheat model to map wheat yield," Remote Sensing of Environment, vol. 112, pp. 1395-1407, 2008.

[48] H. S. Srivastava, T. Sivasankar, and P. K. Sharma, "Biophysical parameters retrieval using RISAT-1 hybrid polarimetric SAR data," National Symposium on 'Recent Advances in Remote Sensing and GIS with Special Emphasis on Mountain Ecosystems', Dehradun, India. 2016

[49] Y. Cui, Y. Yamaguchi, J. Yang, S. E. Park, H. Kobayashi, and G. Singh, "Three-component power decomposition for polarimetric SAR data on adaptive volume scatter modeling," Remote Sensing, vol. 4, pp. 1559-1572, 2012.

[50] Y. Yamaguchi, T. Moriyama, M. Ishido, and H. Yamada, "Fourcomponent scattering model for polarimetric SAR image decomposition," IEEE Transactions on Geoscience and Remote Sensing, vol. 43, no. 8, pp. 1699-1706, 2005

[51] J. C. Souyris, P. Imbo, R. Fjortoft, M. Sandra, and J. S. Lee, "Compact polarimetry basedon symmetry properties of geophysical media: the pi/4 mode," IEEE Transactions on Geoscience and Remote Sensing, vol. 43, pp. 634-646, 2005.

[52] M. Nord, T. Ainsworth, J. S. Lee, and N. Stacy, "Comparison of compact polarimetric synthetic aperture radar modes," IEEE Transactions on Geoscience and Remote Sensing, vol. 47, pp. 174 188, 2009.

[53] R. K. Raney, J. R. S. Cahill, G. W. Patterson, D. Benjamin, and B. J. Bussey, "The m-chi decomposition of hybrid dual-polaimetric radar data with application to lunar craters," Journal of Geophysical Research, vol. 117, no. E12, 2012. DOI: 10.1029/2011JE003986.

[54] C. Prati, F. Rocca, and G. A. Monti, "SAR interferometry experiments with ERS-1," in Proc. of the First ERS-1 Symposium, Cannes, France, pp. 211-218, 1992.

[55] H. S. Srivastava, P. Patel, and R. R. Navalgund, "Application potentials of synthetic aperture radar interferometry for land-use mapping and crop height estimation," Current Science, vol. 91, no. 6, pp. 783-788, 2006.

[56] M. Lavalle, D. Solimini, E. Pottier, and Y. L. Desnos, "Compact polarimetric SAR interferometry," IET Radar, Sonar Navigation, vol. 4, pp. 449-456, 2010.

[57] L. J. Han, Y. Z. Pan, X. L. Zhu, S. Wang, and L. Xu, "Acquisition of paddy rice coverage based on multi-temporal IRS-P6 satellite AWIFS RS-data," Transactions from the Chinese Society of Agricultural Engineering, 2007. DOI: 10.3969/j.issn.10026819.2007.5.025

[58] W. Kubauch, M. J. W. Davidson, R. Steingiesser, K. Dockter, "Investigation of agricultural land use in Italy and Germany by means of the multi-band/multi-frequency SIR-C/X-SAR system," in Proc. of IGARSS '1995, vol. 2, pp. 1061-1063, 1995.

[59] H. McNairn, J. Shang, X. Jiao, and C. Champagne, "The contribution of ALOS PALSAR multipolarization and polarimetric data to crop discrimination," IEEE Transactions on Geoscience and Remote Sensing, vol. 47, no. 12, pp. 3981-3992, 2009.

[60] C. G. J. Schotten, W. W. L. Van Rooy, and L. L. F. Janssen, "Assessment of the capabilities of multi-temporal ERS-1 SAR data to discriminate between agricultural crops," International Journal of Remote Sensing, vol. 16, no. 14, pp. 2619-2637, 1995.

[61] J. S. Lee, M. R. Grunes, and E. Pottier, "Quantitative comparison of classification capability: Fully polarimetric versus dual and singlepolarization SAR," IEEE Transactions on Geoscience and Remote Sensing, vol. 39, no. 11, pp. 2343-2351, 2001.

[62] D. H. Hoekman, M. A. M. Vissers, and T. N. Tran, "Unsupervised full-polarimetric SAR data segmentation as a tool for classification of agricultural areas," IEEE Journal of Selected Topics in Applied Earth Observations and Remote Sensing, vol. 4, no. 2, pp. 402-411, 2011.

[63] Y. Zhang, and L. Wu, "Crop classification by forward neural network with adaptive chaotic particle swarm optimization," Sensors, vol. 11, no. 5, pp. 4721-4743, 2011.

[64] P. Patel, and S. Panigrahy, "Delineation of rice fields affected by flash floodusing temporal RADARSAT Synthetic Aperture Radar data," Spatial Information Technology, Remote Sensing and Geographical Information systems, International conference on Remote Sensing and GIS/GPS-2002, ICORG-2002,B.S.Publications, Hyderabad, vol. 2, pp. 369-373, 2002.

[65] D. Uppala, R. V. Kothapalli, S. Poloju, S. S. V. R. Mullapudi, and V. K. Dadhwal, "Rice crop discrimination using single date RISAT-1 
hybrid (RH, RV) polarimetric data," Photogrammetric Engineering and Remote Sensing, vol. 81, no. 7, pp. 557-563, 2015.

[66] T. Sivasankar, D. Kumar, and H. S. Srivastava, "An investigation of various hybrid polarimetric decomposition techniques for crop discrimination," National Symposium on 'Recent Advances in Remote Sensing and GIS with Special Emphasis on Mountain Ecosystems', Dehradun, India. Dec. 2016.

[67] J. G. P. W. Clevers, and H. J. C. Van Leeuwen, "Combined use of optical and microwave remote sensing data for crop growth monitoring," Remote Sensing of Environment, vol. 55, pp. 42-51, 1996.

[68] G. Fontanelli, S. Paloscia, M. Zribi, and A. Chahbi, "Sensitivity analysis of X-band SAR to wheat and barley leaf area index in the Merguellil basin," Remote Sensing Letters, vol. 4, no. 11, pp. 11071116, 2013.

[69] S. Paloscia, "An empirical approach to estimating leaf area index from multifrequency SAR data," International Journal of Remote Sensing, vol. 19, no. 2, pp. 359-364, 1998.

[70] E. Attema, and F. T. Ulaby, "Vegetation modeled as a Water Cloud," Radio Science, vol. 13, no. 2, pp. 357-364, 1978.

[71] Y. Shao, J. Chen, H. Guo, and H. Lin, "The Potential of Envisat ASAR data in monitoring crop growth," in Proc. of the 2004 Envisat\& ERS Symposium, Salzburg, Austria, pp. 1-5, 2005.

[72] S. Baroti, F. Del Frate, P. Ferrazzoli, S. Paloscia, P. Pampaloni, and G. Schiavon, "SAR polarimetric features of agricultural areas," International Journal of Remote Sensing, vol. 16, no. 14, pp. 26392656, 1995.

[73] I. Choudhury, M. Chakraborty, and J. S. Parihar, "Estimation of rice growth parameter and crop phenology with conjunctive use of RADARSAT and ENVISAT," in Proc. of 'Enisat Symposium 2007', Montreux, Switzerland, pp. 1-6, 2007.

[74] P. Patel, and H. S. Srivastava, "RADARSAT-2 announcement of opportunity project on soil moisture, surface roughness and vegetation parameter retrieval using SAR polarimetry," Technical Report: SAC/EPSA/MPSG/CVD/TDP-R\&D/01/13, Indian Space Research Organisation, Ahmedabad, pp. 1-81, 2013.

[75] F. Wu, B. Zhang, H. Zhang, C. Wang, and Y. Tang, "Analysis of Rice Growth Using Multi-Temporal Radarsat-2 Quad-Pol SAR Images," Intelligent Automation \& Soft Computing, vol. 18, no. 8, pp. 997-1007, 2012.

[76] X. Blaes, P. Defourny, U. Wegmuller, A. D. Vecchina, L. Guerriero, and P. Ferrazzoli, "C-band polarimetric indexes for maize monitoring based on a validated radiative transfer model," IEEE Transactions on Geoscience and Remote Sensing, vol. 44, no. 4, pp. 791-800, 2006.

[77] M. Jia, L. Tong, Y. Chen, Y. Wang, and Y. Zhang, "Rice biomass retrieval from multitemporal ground-based scatterometer data and RADARSAT-2 images using neural networks," Journal of Applied Remote Sensing, vol. 7, no. 1, pp. 073509-073509, 2013.

[78] F. Mattia, G. Satalino, V. R. N. Pauwels, and A. Loew, "Soil moisture retrieval through a merging of multi-temporal L-band SAR data and hydrologic modeling," Hydrology and Earth System Sciences, vol. 13, no. 3, pp. 343-356, 2009.

[79] D. Haldar, M. Chakraborty, K. R. Manjunath, and J. S. Parihar, "Role of polarimetric SAR data for discrimination/biophysical parameters of crops based on canopy architecture," The International Archives of the Photogrammetry, Remote Sensing and Spatial Information Sciences, vol. XL-8, pp. 737-744, 2014.

[80] J. D. Ballester-Berman, J. M. Lopez-Sanchez, and J. Fortuny-Guasch, "Retrieval of biophysical parameters of agricultural crops using polarimetric SAR interferometry," IEEE Transactions on Geoscience and Remote Sensing, vol. 43, no. 4, pp. 683-694, 2005.

[81] S. R. Cloude, and K. P. Papathanassiou, "Three-stage inversion process for polarimetric SAR interferometry," in Proc. of IEE on Radar, Sonar and Navigation, vol. 150, pp. 125-134, 2003.

[82] V. Sellam, and E. Poovammal, "Prediction of crop yield using regression analysis," Indian Journal of Science and Technology, vol. 9 , no. 38, pp. 1-5, 2016

[83] H. Patel, and D. Patel, "A comparative study on various data mining algorithms with special reference to crop yield prediction," Indian Journal of Science and Technology, vol. 9, no. 22, pp. 1-8, 2016.

[84] R. MacDonald, and F. Hall, "Global crop forecasting," Science, vol. 208, no. 4445, pp. 670-679, 1980
[85] P. Artacho, F. Meza, and J. A. Alcalde, "Evaluation of the ORYZA2000 rice growth model under nitrogen-limited conditions in an irrigated Mediterranean environment," Chilean Journal of Agricultural Research, vol. 71, no. 1, pp. 23-33, 2011.

[86] Y. Inoue, E. Sakaiya, and C. Wang, "Potential of X-Band images from high-resolution satellite SAR sensors to assess growth and yield in paddy rice," Remote Sensing, vol. 6, pp. 5995-6019, 2014.

[87] T. Setiyono, A. Nelson, and F. Holecz, "Remote sensing based crop yield monitoring and forecasting," Expert Meeting FAO on Feb 17, 2014.

[88] B. A. M. Bouman, M. J. Kropff, T. P. Tuong, M. C. S. Wopereis, H. F. M. Ten Berge, and H. H. Van Laar, "ORYZA2000:modeling lowland rice," International Rice Research Institute, pp. 1-235, 2001. ISBN: 9712201716

[89] Y. Shao, X. Fan, H. Liu, J. Xiao, S. Ross, B. Brisco, R. Brown, and G. Staples, "Rice monitoring and production estimation using multitemporal RADARSAT," Remote Sensing of Environment, vol. 76, pp. 310-325, 2001.

[90] P. Patel, H. S. Srivastava, and R. R. Navalgund, "Estimating wheat yield: An approach for estimating number of grains using crosspolarized Envisat-1 ASAR data," Microwave Remote Sensing of the Atmosphere and Environment V, Proc. of SPIE, vol. 6410, no. 641009, pp. 01-12, 2006.

[91] F. T. Ulaby, K. Sarabandi, and M. C. Dobson, "Development of SAR algorithm for mapping soil moisture and vegetation biomass," Technical Report 032601-F, University of Michigan, pp. 1-24, 1999.

[92] M. S. Moran, L. Alonso, J. F. Moreno, M. P. C. Mateo, D. Fernando de la Cruz, and A. Montoro, "A RADARSAT-2 quad-polarized time series for monitoring crop and soil conditions in Barrax, Spain," IEEE Transactions on Geoscience and Remote Sensing, vol. 50, no. 4, pp. 1057-1070, 2012.

[93] F. Wu, C. Wang, H. Zhang, B. Zhang, and Y. Tang, "Rice crop monitoring in south China with Radarsat-2 quad-polarization SAR data," IEEE Geoscience and Remote Sensing Letters, vol. 8, no. 2, pp. 196-200, 2011.

[94] S. Paloscia, S. Pettinato, and E. Santi, "Combining L- and X-band SAR data for estimating biomass and soil moisture of agricultural fields," European Journal of Remote Sensing, vol. 45, pp. 99-109, 2012.

[95] M. W. Jang, Y. H. Kim, N. W. Park, and S. Y. Hong, "Mapping paddy rice varieties using multi-temporal Radarsat SAR images," Korean Journal of Remote Sensing, vol. 28, no. 6, pp. 653-660, 2012

[96] Y. Kim, T. Jackson, H. Lee, and S. Hong, "Radar vegetation index for estimating the vegetation water content of rice and soybean," IEEE Geoscience and Remote Sensing Letters, vol. 9, no. 4, pp. 564568, 2012.

[97] Y. Inoue, and E. Sakaiya, "Relationship between X-band backscatter coefficients from high resolution satellite SAR and biophysical variables in paddy rice," Remote Sensing Letters, vol. 4, no. 3, pp. 288-295, 2013.

[98] T. Emmerik, S. C. Steele-Dunne, J. Judge, and N. van de Giesen, "Impact of diurnal variation of vegetation in vegetation water content on radar backscatter from maize during water stress," IEEE Transactions on Geoscience and Remote Sensing, vol. 53, no. 7, pp. 3855-3869, 2015.

[99] C. P. Tan, H. T. Ewe, and H. T. Chuah, "Agricultural crop-type classification of multi-polarization SAR images using a hybrid entropy decomposition and support vector machine technique," International Journal of Remote Sensing, vol. 32, no. 22, pp. $7057-$ 7071, 2011.

[100] J. M. Lopez-Sanchez, D. Ballester-Berman, and Y. Marquez-Moreno, "Model limitations and parameter estimation methods for agricultural applications of polarimetric SAR interferometry," IEEE Transactions on Geoscience and Remote Sensing, vol. 45, no. 11, pp. 3481-3493, 2007.

[101] M. Engdahl, Multi-temporal InSAR in land-cover mapping and vegetation mapping. Doc. Thesis. Aalto University, pp. 1-119, 2013. [102] E. Erten, J. M. Lopez-Sanchez, O. Yuzugullu, and I. Hajnsek, "Retrieval of agricultural crop height from space: A comparison of SAR techniques," Remote Sensing of Environment, vol. 187, pp. 130-144, 2016. 